OPEN ACCESS

Edited by:

Tamotsu Oomori

University of the Ryukyus, Japan

Reviewed by:

Sylvain Agostini,

Shimoda Marine Research Center,

Japan

*Correspondence:

Neil C. S. Chan

nchancs@gmail.com

Specialty section: This article was submitted to

Coral Reef Research,

a section of the journal

Frontiers in Marine Science

Received: 06 April 2017 Accepted: 06 July 2017

Published: 25 July 2017

Citation:

Chan NCS, Wangpraseurt D, Kühl M and Connolly SR (2017) Corrigendum:

Flow and Coral Morphology Control Coral Surface $\mathrm{pH}$ : Implications for the Effects of Ocean Acidification.

Front. Mar. Sci. 4:226.

doi: 10.3389/fmars.2017.00226
Corrigendum: Flow and Coral Morphology Control Coral Surface $\mathrm{pH}$ : Implications for the Effects of Ocean Acidification

\author{
Neil C. S. Chan ${ }^{1 *}$, Daniel Wangpraseurt ${ }^{2,3}$, Michael Kühl $^{2,3}$ and Sean R. Connolly ${ }^{1,4}$ \\ ${ }^{1}$ Department of Marine Biology, College of Marine and Environmental Sciences, James Cook University, Townsville, QLD, \\ Australia, ${ }^{2}$ Department of Ocean Microbiology, Plant Functional Biology and Climate Change Cluster, University of \\ Technology Sydney, Sydney, NSW, Australia, ${ }^{3}$ Marine Biology Section, Department of Biology, University of Copenhagen, \\ Helsingor, Denmark, ${ }^{4}$ ARC Centre of Excellence for Coral Reef Studies, James Cook University, Townsville, QLD, Australia
}

Keywords: climate change, carbonate chemistry, calcification, diffusive boundary layer

\section{A corrigendum on}

Flow and Coral Morphology Control Coral Surface pH: Implications for the Effects of Ocean Acidification

by Chan, N. C. S., Wangpraseurt, D., Kühl, M., and Connolly, S. R. (2016). Front. Mar. Sci. 3:10. doi: 10.3389/fmars.2016.00010

In the original article there was a mistake in the units of the $y$ axis and corresponding legend of Figure 1 as published. The correct version of Figure 1 appears below. The authors apologize for the mistake. This error does not change the scientific conclusions of the article in any way.

Conflict of Interest Statement: The authors declare that the research was conducted in the absence of any commercial or financial relationships that could be construed as a potential conflict of interest.

Copyright (๑) 2017 Chan, Wangpraseurt, Kühl and Connolly. This is an open-access article distributed under the terms of the Creative Commons Attribution License (CC BY). The use, distribution or reproduction in other forums is permitted, provided the original author(s) or licensor are credited and that the original publication in this journal is cited, in accordance with accepted academic practice. No use, distribution or reproduction is permitted which does not comply with these terms. 

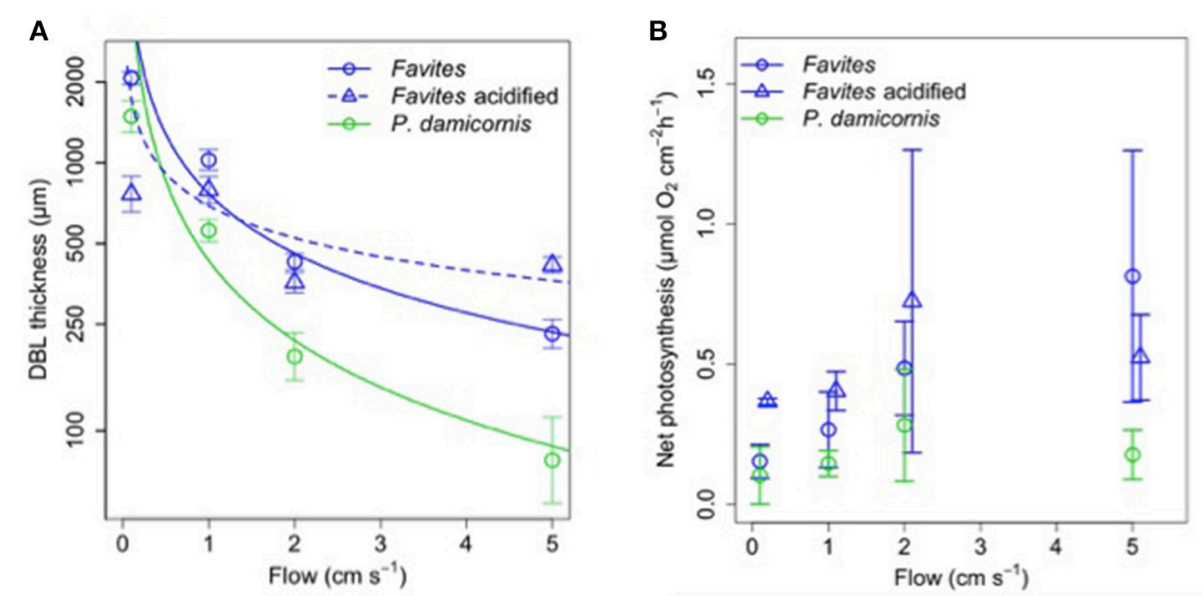

FIGURE 1 | (A) DBL thickness ( $\mu \mathrm{m})$ vs. flow $\left(\mathrm{cm} \mathrm{s}^{-1}\right)$ for Favites (blue circles), Favites under acidified conditions (blue triangles) and P. damicornis (green circles). Symbols and error bars represent the mean $\pm 1.96^{*} \mathrm{SE}(n=2-6)$. Lines represent the relationship between DBL thickness and flow from fitted power functions (blue solid-DBL Favites $=767$ flow $^{-0.738}$, blue dashed-DBLFavites acidified $=691$ flow $^{-0.399}$, green solid-DBLP.damicornis $=432$ flow ${ }^{-0.99}$ ). (B) Net photosynthesis $\left(\mu \mathrm{mol} \mathrm{O}_{2} \mathrm{~cm}^{-2} \mathrm{~h}^{-1}\right.$ ) at various flows ( $\mathrm{cm} \mathrm{s}^{-1}$ ) for Favites (blue circles), Favites under acidified conditions (blue triangles) and $P$. damicornis (green circles). Symbols with error bars represent the mean $\pm 1.96 \star S E(n=2-6)$. 